\title{
Fatty Acid Increases cAMP-dependent Lactate and MAO-B-dependent GABA Production in Mouse Astrocytes by Activating a $\mathrm{G}_{\mathrm{as}}$ Protein-coupled Receptor
}

\author{
NaHye Lee $e^{1,2,3 \dagger}$, Moonsun Sa ${ }^{4,5,6 \dagger}$, Yu Ri Hong ${ }^{2}$, C. Justin Lee ${ }^{4,5,6 *}$ and JaeHyung Koo ${ }^{2,3 *}$ \\ ${ }^{1}$ Department of Brain and Cognitive Sciences, DGIST, Daegu 42988, ${ }^{2}$ Department of New Biology, DGIST, Daegu 42988, \\ ${ }^{3}$ Center for Bio-Convergence Spin System, DGIST, Daegu 42988, ${ }^{4}$ KU-KIST Graduate School of Converging Science and \\ Technology, Korea University, Seoul 02841, ${ }^{5}$ Center for Neuroscience and Functional Connectomics, Korea Institute of Science \\ and Technology (KIST), Seoul 02792, ${ }^{6}$ Center for Glia-Neuron Interaction, KIST, Seoul 02792, Korea
}

\begin{abstract}
Medium-chain fatty acids (MCFAs) are mostly generated from dietary triglycerides and can penetrate the blood-brain barrier. Astrocytes in the brain use MCFAs as an alternative energy source. In addition, MCFAs have various regulatory and signaling functions in astrocytes. However, it is unclear how astrocytes sense and take up MCFAs. This study demonstrates that decanoic acid (DA; C10), a saturated MCFA and a ligand of $\mathrm{G}_{\mathrm{as}}$ protein-coupled receptors ( $\mathrm{G}_{\mathrm{as}}-\mathrm{GPCRs}$ ), is a signaling molecule in energy metabolism in primary astrocytes. cAMP synthesis and lactate release were increased via a putative $\mathrm{G}_{\mathrm{as}}-\mathrm{GPCR}$ and transmembrane adenylyl cyclase upon short-term treatment with DA. By contrast, monoamine oxidase B-dependent gamma-aminobutyric acid (GABA) synthesis was increased in primary cortical and hypothalamic astrocytes upon long-term treatment with DA. Thus, astrocytes respond to DA by synthesizing cAMP and releasing lactate upon short-term treatment, and by synthesizing and releasing GABA upon long-term treatment, similar to reactive astrocytes. Our data suggest that astrocytes in the brain play crucial roles in lipid-sensing via GPCRs and modulate neuronal metabolism or activity by releasing lactate via astrocyte-neuron lactate shuttle or GABA to influence neighboring neurons.
\end{abstract}

Key words: astrocytes, medium-chain fatty acids, cAMP, lactate, decanoic acid, gamma-aminobutyric acid

\section{INTRODUCTION}

The major cause of metabolic disorders such as obesity is in-

Received October 2, 2018, Revised October 20,2018,

Accepted October 24, 2018

* To whom correspondence should be addressed.

JaeHyung Koo, TEL: 82-53-785-6112, FAX: 82-53-785-1819

e-mail:jkoo001@dgist.ac.kr

C. Justin Lee, TEL: 82-2-958-6940, FAX: 82-2-958-6919

e-mail: cjl@kist.re.kr

"These authors contributed equally to this work. creased consumption of a high-calorie diet. Chronic intake of a high-fat diet (HFD) increases not only the level of fat in the peripheral system, but also uptake of fatty acids (FAs) into the brain from the plasma $[1,2]$. Enrichment of saturated FAs causes lipid accumulation in the brain, especially the hypothalamus [3-5]. Moreover, free FAs accumulate in astrocytes and neurons in the brain $[6,7]$. However, it is unclear how FAs accumulate in astrocytes and how free FAs affect the control of energy balance and feeding.

Treatment with long-chain FAs (C13 C21) increases inflammatory responses in cultured astrocytes, despite the fact that these 
molecules cannot cross the blood-brain barrier (BBB) [8-10]. On the other hand, medium-chain FAs (MCFAs; C6 C12), such as octanoic acid (OA; C8) and decanoic acid (DA; C10), can cross the BBB and are rapidly metabolized in the brain $[11,12]$. These molecules modulate energy metabolism in astrocytes [13]. Along with their role in supplying an energy source, FAs regulate various intracellular signaling pathways and modulate mitochondrial energy production [13]. In particular, FAs are ligands for many $G$ protein-coupled receptors (GPCRs) and members of the free FA receptor (FFAR) family. This family consists of FFAR1/GPR40, FFAR2/GPR43, FFAR3/GPR41, and FFAR4/GPR120, which recognize free FAs [14]. FFAR2 and FFAR3 recognize small-chain FAs (SCFAs; C1 C6). Odorant receptors (ORs), which comprise the largest subfamily of GPCRs, also recognize SCFAs and free FAs [15-17]. Among MCFAs, DA increases glycolysis and lactate synthesis in astrocytes $[11,18]$. MCFAs may have beneficial effects in the brain by activating metabolic shuttle systems that provide an energy source to neighboring neurons in the form of lactate and ketone bodies [18]. Stimulation with MCFAs increases glycolytic activity and consequently induces release of lactate by astrocytes into the extracellular space [19-21]. However, little is known about the molecular mechanism by which astrocytes sense free FAs and increase lactate release, and by which GPCRs recognize free FAs in astrocytes.

There are more astrocytes than neurons in most regions of the human brain $[22,23]$. Astrocytes play a vital role in metabolism by oxidizing FAs to produce ketone bodies, which are an energy source for neurons [24]. In addition, astrocytes regulate energy homeostasis upon short-term exposure to a HFD by metabolizing lipids under physiological conditions [25, 26]. However, the roles of astrocytes are altered upon chronic exposure to a HFD [27-29]. Hypertrophic and hyperplasic astrocytes, which are conventionally called reactive astrocytes, are observed in the rodent hypothalamus after exposure to a HFD for $24 \mathrm{~h}$ or longer [29]. Recent studies suggest that hypertrophic and hyperplasic astrocytes can be divided into two categories, namely, active astrocytes, which express proBDNF, and reactive astrocytes, which express gammaaminobutyric acid (GABA) [30]. Moreover, proBDNF and GABA have a reciprocal relationship, meaning that aberrant release of GABA might suppress proBDNF expression [30,31]. Astrocytic GABA is synthesized by monoamine oxidase $\mathrm{B}$ (MAO-B), which is mainly expressed in astrocytes [32]. MAO-B mediates degradation of the polyamine putrescine, which is a byproduct of toxin degradation, to generate GABA [32, 33]. However, it is uncertain whether long-term exposure to MCFAs leads to generation of active or reactive astrocytes.

This study investigated how astrocytes sense free FAs and deter- mined whether astrocytes are active or reactive after short-term and long-term treatment with DA. We treated primary astrocytes with DA and examined whether they sense this MCFA via a GPCR. In addition, we investigated whether long-term exposure to $\mathrm{DA}$ increases $\mathrm{GABA}$ synthesis via $\mathrm{MAO}-\mathrm{B}$, as occurs in reactive astrocytes.

\section{MATERIALS AND METHODS}

\section{Culture of primary cortical astrocytes for the cAMP assay}

Primary astrocytes were obtained from the cerebral cortex of a E18.5 mouse embryo and cultured as previously described [34], with minor modifications. A total of $1.2 \times 10^{7}$ mixed glial cells were seeded in a poly-D-lysine-coated T75 flask. After $2 \mathrm{~h}$, the plating medium was replaced by mixed glial cell growth medium, Dulbecco's modified Eagle's medium (DMEM; Thermo Fisher Scientific, MA) supplemented with $10 \%$ fetal bovine serum (FBS; Thermo Fisher Scientific, MA) and 1\% penicillin/streptomycin). The medium was changed every 3 days for 2 weeks. Thereafter, the mixed glial culture medium, which contained floating primary microglia, was discarded and the T75 flask was shaken at $160 \mathrm{rpm}$ for 1 day in a shaking incubator to completely remove primary microglia. Following treatment with $0.25 \%$ trypsin, astrocytes were collected, replated in a T75 flask, and cultured for 4 days to increase their purity. Finally, samples were treated with $0.25 \%$ trypsin, and then shaken at $160 \mathrm{rpm}$ for $7 \mathrm{~h}$ and lightly tapped to accelerate the isolation of astrocytes. A known number of astrocytes was mixed with fresh culture medium for subsequent experiments.

\section{Lactate assay}

Lactate release by primary astrocytes was measured using a Lactate Assay Kit (BioVision, Mountain View, CA), according to the manufacturer's instructions. This kit included lactate assay buffer, standard lactate, lactate substrate mix, and lactate enzyme mix. Primary astrocytes were seeded in a 6 -well plate $\left(1 \times 10^{6}\right.$ cells/ well) and maintained at $37^{\circ} \mathrm{C}$ in a humidified incubator containing $5 \% \mathrm{CO}_{2}$ for 2 days. Thereafter, cells were treated with vehicle, 1 $\mathrm{mM}$ glucose, various concentrations (10, 30, 100, 300, 600, 1,000, and $1,200 \mu \mathrm{M}$ ) of DA for $1 \mathrm{~h}$, or $100 \mu \mathrm{M}$ DA for various durations in lactate assay buffer. In some experiments, cells were pretreated with $1 \mathrm{mM}$ SQ22536 and/or $10 \mu \mathrm{M}$ gallein for $1 \mathrm{~h}$. Lactate release was measured by incubating $50 \mu \mathrm{l}$ of the supernatant, $2 \mu$ lactate substrate mix, and $2 \mu$ lactate enzyme mix in a 96-well enzymelinked immunosorbent assay (ELISA) plate for $30 \mathrm{~min}$. The lactate concentration was calculated for the known lactate standard in the kit. The optical density at $450 \mathrm{~nm}$ was measured using a VersaMax microplate reader (Molecular Devices, CA). 


\section{cAMP ELISA assay}

The level of cAMP was quantified using a Direct cAMP ELISA kit with the non-acetylated cAMP standard format (Enzo Life Sciences, NY). A competitive cAMP ELISA was performed according to the manufacturer's protocol. In brief, primary astrocytes were seeded in a 48 -well plate $\left(5 \times 10^{4}\right.$ cells/well $)$ and maintained in a humidified incubator containing $5 \% \mathrm{CO}_{2}$ at $37^{\circ} \mathrm{C}$ for 2 days. Thereafter, the cells were treated with vehicle, $30 \mu \mathrm{M}$ forskolin, or various concentrations $(10,30,100,300,600$, and 1,000 $\mu \mathrm{M})$ of DA in Hank's balanced salt solution for $30 \mathrm{~min}$. In some experiments, cells were pretreated with $1 \mathrm{mM}$ SQ22536 for $1 \mathrm{~h}$. cAMP was extracted by lysing the cell pellet in $200 \mu \mathrm{l}$ of $0.1 \mathrm{M} \mathrm{HCl}$ containing $1 \%$ Triton X-100 for $10 \mathrm{~min}$ followed by centrifugation at $600 \times \mathrm{g}$ for $2 \mathrm{~min}$ to remove cellular debris. To quantify cAMP, $100 \mu \mathrm{l}$ of the supernatant was analyzed using a Direct cAMP ELISA kit according to the manufacturer's protocol. All incubation steps were performed at room temperature. The optical density at $405 \mathrm{~nm}$ was measured using a VersaMax microplate reader.

\section{Culture of primary cortical and hypothalamic astrocytes for immunocytochemistry}

Primary astrocytes were obtained from C57BL/6J mouse pups at P0 P2. The cerebral cortex was dissected and the meninges were removed. The entire hypothalamus was dissected, minced, and dissociated into a single-cell suspension via gentle trituration through a Pasteur pipette. Dissociated cells were seeded in a 35 $\mathrm{mm}$ plate coated with $0.1 \mathrm{mg} / \mathrm{ml}$ poly-D-lysine. Cells were grown in DMEM supplemented with $25 \mathrm{mM}$ glucose, $2 \mathrm{mM}$ glutamine, $10 \%$ heat-inactivated horse serum, 10\% heat-inactivated FBS, and $1 \%$ penicillin-streptomycin. On the third day of culture, cells were washed by repeated pipetting and the medium was replaced to remove debris and other floating cell types. For DA treatment, cells were transferred to a 24-well plate containing coverslips coated with $0.1 \mathrm{mg} / \mathrm{ml}$ poly-D-lysine (Sigma-Aldrich, MO) after 11 days in vitro (DIV). The next day, the medium was replaced by DMEM containing $25 \mathrm{mM}$ glucose, $2 \mathrm{mM}$ glutamine, 5\% heat-inactivated horse serum, $5 \%$ heat-inactivated FBS, $1 \%$ penicillin-streptomycin, and 10,30 , or $100 \mu \mathrm{M}$ DA. Cultured cells were maintained at $37^{\circ} \mathrm{C}$ in a humidified incubator containing $5 \% \mathrm{CO}_{2}$.

\section{Immunocytochemistry}

Primary astrocytes cultured in a 24-well plate were fixed in 4\% paraformaldehyde and 0.5\% glutaraldehyde (Sigma, G5882-50 $\mathrm{ML}$ ) for $15 \mathrm{~min}$ at room temperature after $13 \mathrm{DIV}$, and washed with $0.1 \mathrm{M}$ phosphate-buffered saline (PBS) for $5 \mathrm{~min}$. Samples were incubated with $0.1 \mathrm{M}$ PBS containing $0.3 \%$ Triton X-100 (Sigma) and $10 \%$ donkey serum (Genetex, CA) for $1.5 \mathrm{~h}$ to prevent non-specific binding. Cells were incubated with a guinea-pig antiGABA antibody (ab175; 1:1000; Millipore, MA) and a chicken anti-glial fibrillary acidic protein (GFAP) antibody (ab5541; 1:1000; Millipore) overnight at $4^{\circ} \mathrm{C}$. After washing with $0.1 \mathrm{M}$ PBS, cells were incubated with a DyLight 488- or 594-conjugated secondary antibody (1:500; Jackson Laboratory, ME) for $2 \mathrm{~h}$ at room temperature. After three rinses with $0.1 \mathrm{M} \mathrm{PBS}$ and staining with DAPI (1:3000; Thermo Scientific, MA), coverslips were mounted on Polysine microscopic glass slides (Thermo Scientific, MA). Images were acquired using a Nikon A1R confocal microscope.

\section{Image quantification}

Confocal microscopic images were analyzed using Image (NIH). To analyze the fluorescence intensity of GABA labeling in each astrocyte, images were converted to a binary format and each GFAPpositive astrocyte was identified as a region of interest. The mean fluorescence intensity of GABA labeling was measured in each region of interest. Thus, the fluorescence intensity of GABA labeling was only measured in GFAP-positive astrocytes.

\section{RESULTS}

\section{DA increases cAMP synthesis via a $G_{a s}-G P C R$ in primary cortical astrocytes}

DA is a saturated MCFA that directly stimulates lactate synthesis in astrocytes by modulating their metabolism and supplies an energy source to neighboring neurons via activation of the astrocyteneuron shuttle $[12,18]$. Bicarbonate-responsive lactate coupling between astrocytes and neurons is reportedly due to enhanced intracellular cAMP formation via activation of soluble adenylyl cyclase (sAC) [35]. We therefore investigated whether cAMP synthesis mediates DA-induced lactate production in astrocytes. To this end, we treated primary cortical astrocytes with different concentrations $(0,10,30,100,300,600$, and $1,000 \mu \mathrm{M})$ of DA for 30 min and then measured the intracellular level of cAMP. DA treatment significantly $(\mathrm{p}<0.001)$ increased the intracellular cAMP concentration in a dose-dependent manner (Fig. 1A). Similarly, the intracellular cAMP concentration was increased by treatment with forskolin, which activates transmembrane adenylyl cyclase (tmAC) but not sAC (Fig. 1). DA showed agonistic activity for cAMP production and had an $\mathrm{EC}_{50}$ of $82.5 \mu \mathrm{M}$. Mammalian sAC is insensitive to $\mathrm{G}$ proteins, forskolin, which is a tmAC-specific activator, and SQ22536, which is a tmAC-specific inhibitor [36, 37]. By contrast, tmAC is sensitive to Gs-protein of GPCRs, forskolin, and SQ22536. Thus, we examined whether DA-stimulated intracellular cAMP formation is dependent on tmAC. The intracellular cAMP concentration was significantly $(\mathrm{p}<0.001)$ higher in for- 
A

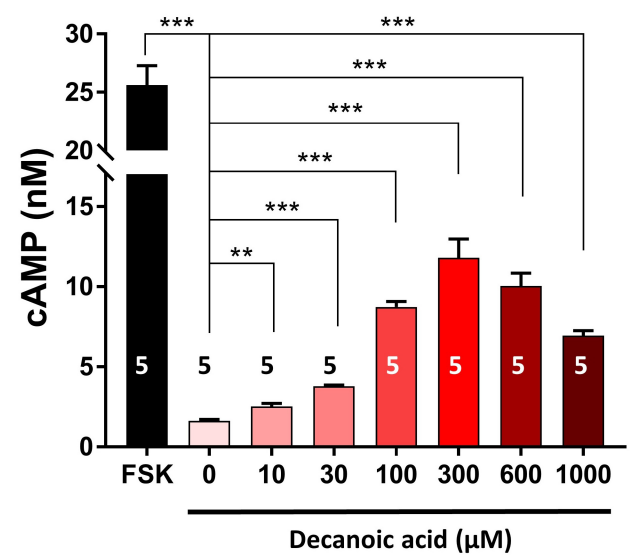

B

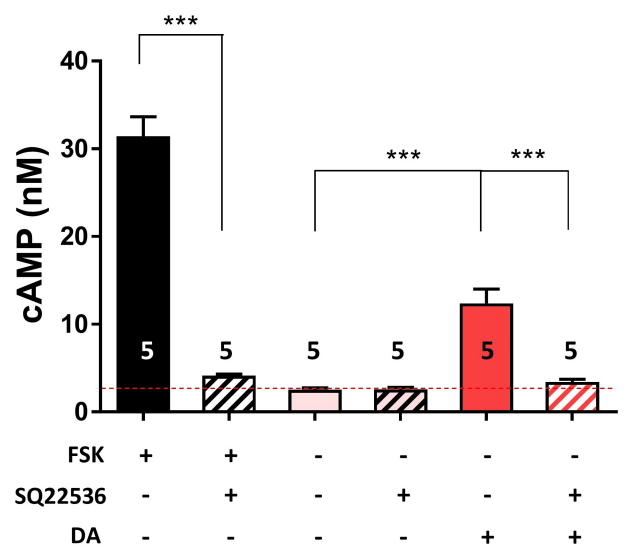

Fig. 1. DA increases cAMP synthesis via a $G_{a s}$-GPCR. (A) The intracellular cAMP concentration was measured in primary astrocytes treated with different concentrations $(0,10,30,100,300,600$, and $1,000 \mu \mathrm{M})$ of DA for $30 \mathrm{~min}$. Alternatively, primary astrocytes were treated with $30 \mu \mathrm{M}$ forskolin (FSK), a tmAC-specific activator, as a positive control. (B) The intracellular cAMP concentration was measured in primary astrocytes treated with $100 \mu \mathrm{M}$ DA with or without pretreatment with $1 \mathrm{mM}$ SQ22536 for $1 \mathrm{~h}$, which is a tmAC-specific inhibitor. The red dotted line indicates the basal level of lactate release in untreated cells. All data are shown as mean $\pm \operatorname{SEM}(n=5)$ and were analyzed using the Student's $t$ test. ${ }^{*} \mathrm{p}<0.05,{ }^{* *} \mathrm{p}<0.01,{ }^{* * *} \mathrm{p}<0.001$.

A

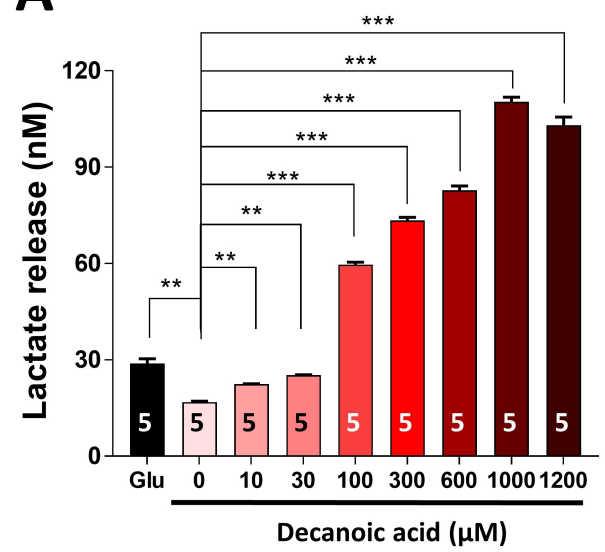

B

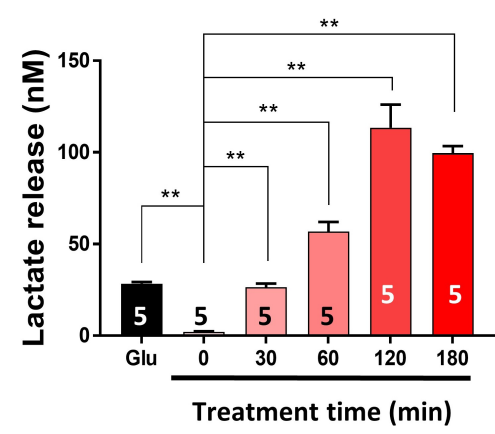

C

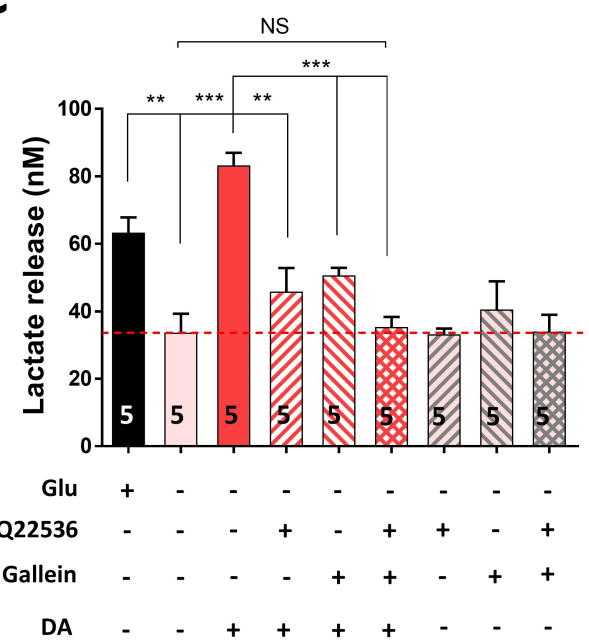

Fig. 2. DA increases lactate release via a $G_{a s}-G P C R$. (A, B) Lactate release was measured in primary astrocytes treated with different concentrations ( 0 , $10,30,100,300,600,1,000$, and $1,200 \mu \mathrm{M})$ of DA for $1 \mathrm{~h}(\mathrm{~A})$ or with $100 \mu \mathrm{M}$ DA for different durations $(0,30,60,120$, and 180 min) (B). Glucose (Glu) was used as a positive control. (C) Lactate release was measured in primary astrocytes pretreated with or without SQ22536 (a tmAC inhibitor) and/or gallein ( $\mathrm{a}_{\beta \gamma}$ signaling inhibitor) for $1 \mathrm{~h}$ and then treated with $100 \mu \mathrm{M}$ DA. The red dotted line indicates the basal level of lactate release in untreated cells. All data are shown as mean $\pm \operatorname{SEM}(n=5)$ and were analyzed using the Student's $t$ test. ${ }^{*} \mathrm{p}<0.05,{ }^{* *} \mathrm{p}<0.01,{ }^{* * *} \mathrm{p}<0.001$, NS, not significant.

skolin- and DA-treated astrocytes than in untreated astrocytes (Fig. 1B). SQ22536 significantly $(\mathrm{p}<0.001)$ attenuated the DA- and forskolin-induced increases in the intracellular cAMP concentration by $90.88 \%$ and $94.42 \%$, respectively (Fig. 1B). Collectively, these data suggest that DA induces synthesis of cAMP via coupling of a $\mathrm{G}_{\mathrm{as}}$-GPCR with tmAC, but not with sAC. These results are consistent with the brain RNA sequencing transcriptome [38, 39], which showed that nine tmACs (ADCY1 9) are uniformly expressed in astrocytes, while only one sAC $(A D C Y 10)$ is extremely lowly expressed. Interestingly, mRNA expression of $A D C Y 2$ is highest in mouse and mature human astrocytes.

\section{DA increases lactate release via a $G_{a s}-G P C R$ in primary cor- tical astrocytes}

Next, we investigated whether DA stimulates the production and release of lactate via tmAC-mediated cAMP synthesis. To this end, 
we treated primary cortical astrocytes with different concentrations $(0,10,30,100,300,600,1,000$, and 1,200 $\mu \mathrm{M})$ of DA for $1 \mathrm{~h}$ and with $100 \mu \mathrm{M}$ DA for different durations $(0,30,60,120$, and $180 \mathrm{~min})$. DA treatment significantly $(\mathrm{p}<0.01)$ increased lactate release in a dose-dependent (Fig. 2A) and time-dependent (Fig. $2 \mathrm{~B})$ manner. The $\mathrm{EC}_{50}$ of DA was $209.2 \mu \mathrm{M}$. To determine whether a $\mathrm{G}_{\mathrm{as}}$-GPCR mediates DA-induced lactate release, we pretreated primary cortical astrocytes with SQ22536, a $\mathrm{G}_{\mathrm{as}}$-mediated tmACspecific inhibitor, and/or gallein, $\mathrm{a}_{\beta \gamma}$ signaling inhibitor, and then treated them with DA (Fig. 2C). Pretreatment with SQ22536 and gallein significantly $(\mathrm{p}<0.001)$ attenuated the DA-induced increase in lactate release by $75.53 \%$ and $65.71 \%$, respectively (Fig. 2C). In addition, pretreatment with both SQ22536 and gallein almost completely $(\mathrm{p}<0.001)$ abolished the DA-induced lactate release (96.68\%). Taken together, these results suggest that DA increases lactate release via a $\mathrm{G}_{\mathrm{as}}$-coupled GPCR.

\section{$D A$ increases GABA production in primary cortical astrocytes}

Resting astrocytes transform into reactive astrocytes upon ad- verse stimulations, such as toxin challenges, which is usually accompanied by neuroinflammation [30]. Continuous and excessive consumption of dietary fats activates the inflammatory response in the hypothalamus, leading to generation of reactive astrocytes $[27,29]$. Therefore, we tested whether long-term treatment with DA leads to the generation of reactive astrocytes by assessing the level of GABA, which is a marker of reactive astrocytes $[29,30]$, and by co-staining with GFAP, which is a marker of astrocytes. Primary cortical astrocytes were split after 11 DIV and incubated with DA after 12 DIV for $24 \mathrm{~h}$ (Fig. 3A). DA treatment increased the GABA level in a dose-dependent manner (Fig. 3B). The GABA level was significantly $(\mathrm{p}<0.001)$ increased in cells treated with 100 $\mu \mathrm{M}$ DA (Fig. 3C). Together, these findings indicate that long-term treatment with DA increases the level of GABA in cortical astrocytes in a dose-dependent manner.

\section{$D A$ increases $G A B A$ production via $M A O-B$ in primary cor- tical astrocytes}

MAO-B generated from putrescine mediates GABA produc-
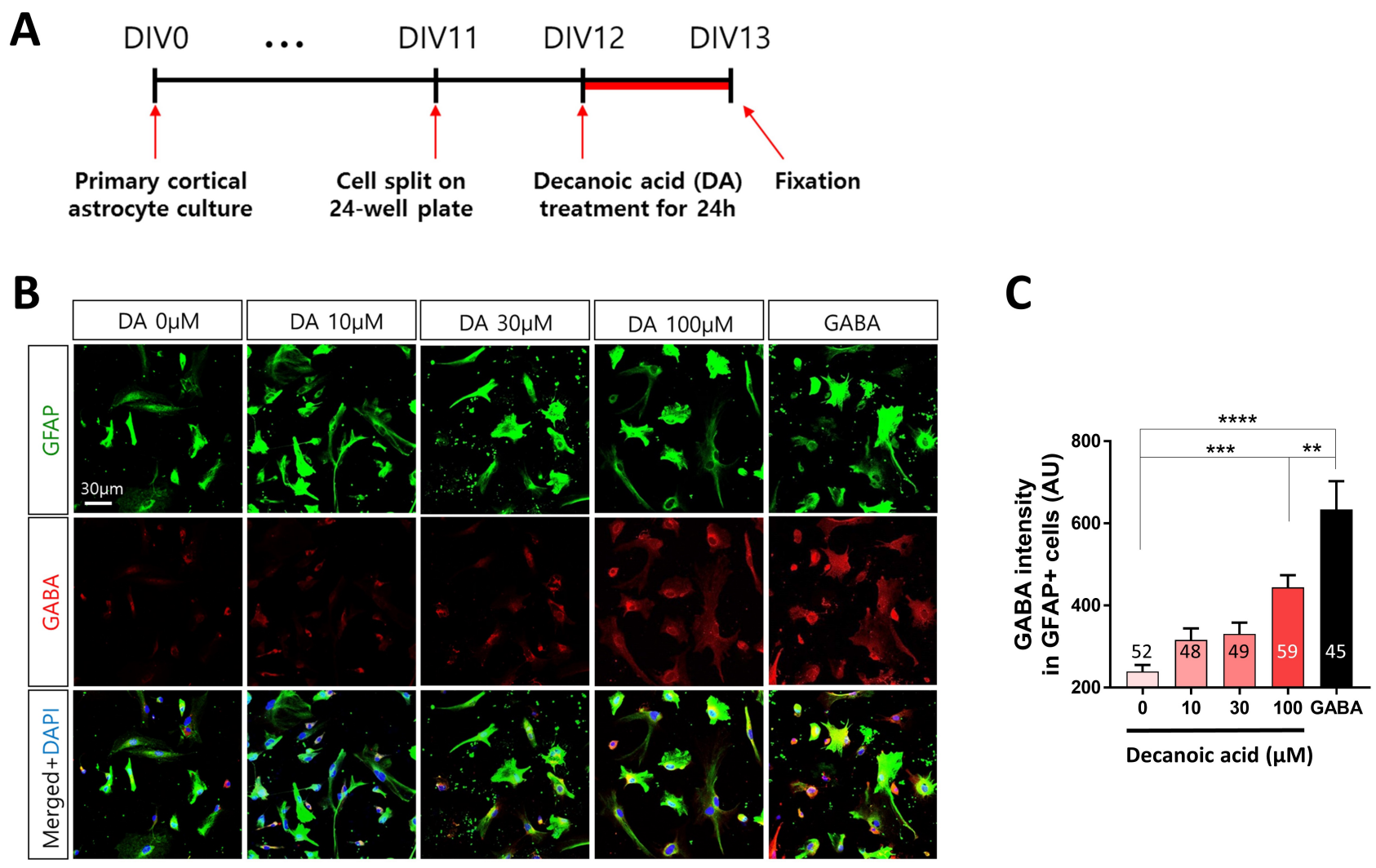

Fig. 3. DA increases GABA production in primary cortical astrocytes. (A) Timeline of treatment of primary cortical astrocytes with different concentrations of DA for $24 \mathrm{~h}$ followed by immunocytochemistry. (B) Representative fluorescence immunocytochemical images of cells treated with different concentrations $(0,10,30$, and $100 \mu \mathrm{M})$ of DA. Cells were treated with $100 \mu \mathrm{M}$ GABA as a positive control. (C) Fluorescence intensity of GABA labeling in GFAP-positive primary cortical astrocytes. All data are shown as mean \pm SEM $(0 \mu \mathrm{M}, \mathrm{n}=52$ cells; $10 \mu \mathrm{M}, \mathrm{n}=48$ cells; $30 \mu \mathrm{M}, \mathrm{n}=49$ cells; $100 \mu \mathrm{M}, \mathrm{n}=59$ cells; and GABA, $n=45$ cells) and were analyzed using Tukey's multiple comparison test. ${ }^{*} \mathrm{p}<0.05,{ }^{* *} \mathrm{p}<0.01,{ }^{* * *} \mathrm{p}<0.001,{ }^{* * *} \mathrm{p}<0.0001$. 

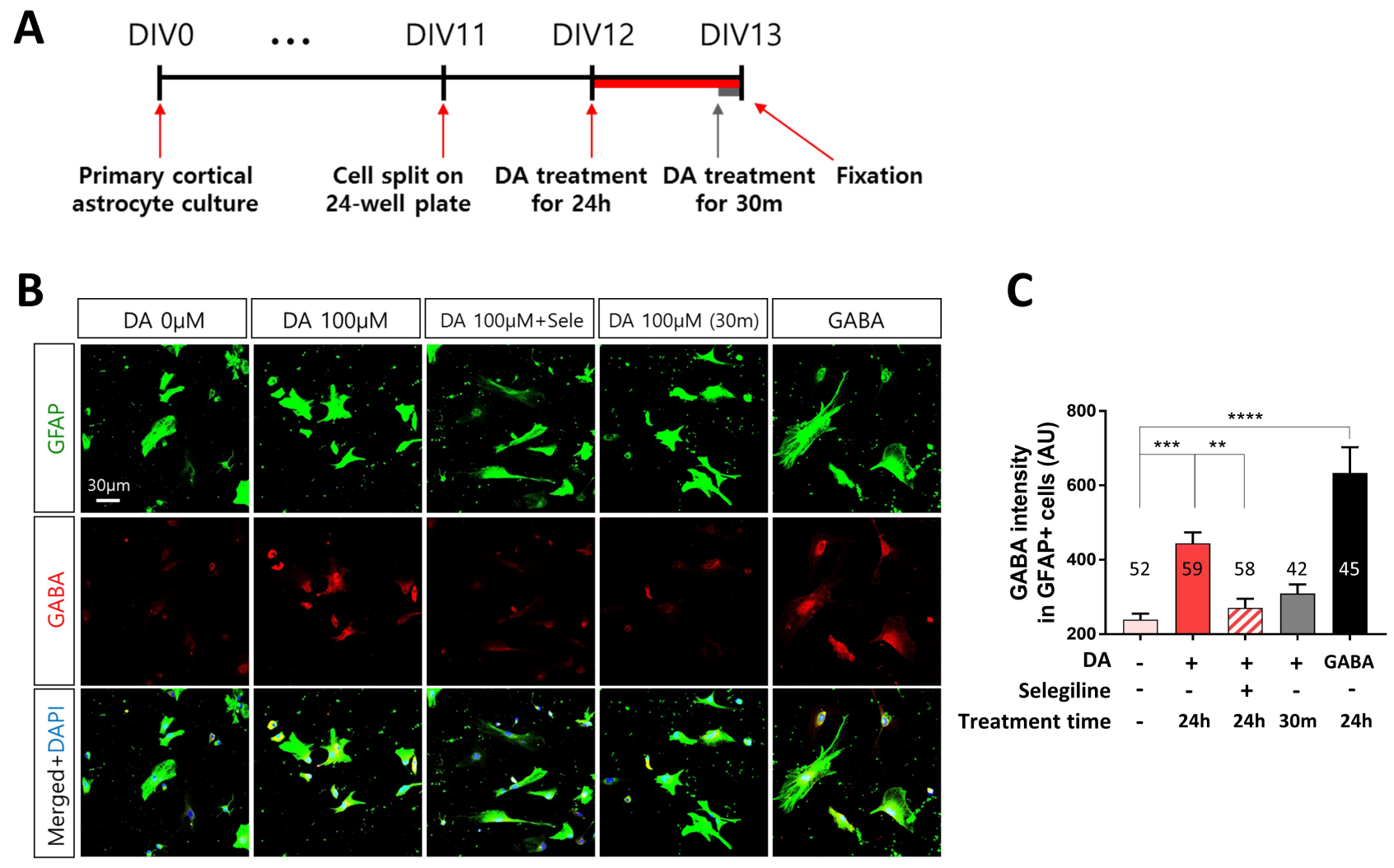

Fig. 4. DA increases GABA production via MAO-B in primary cortical astrocytes. (A) Timeline of treatment of primary cortical astrocytes with DA for $24 \mathrm{~h}$ or $30 \mathrm{~min}$ followed by immunocytochemistry. (B) Representative fluorescence immunocytochemical images of cells treated with $100 \mu \mathrm{M}$ DA for different durations. Cells were treated with $100 \mu \mathrm{M}$ GABA as a positive control. (C) Fluorescence intensity of GABA labeling in GFAP-positive primary cortical astrocytes. All data are shown as mean \pm SEM $(0 \mu \mathrm{M}, \mathrm{n}=52$ cells; $100 \mu \mathrm{M}$ for $24 \mathrm{~h}, \mathrm{n}=59$ cells; $100 \mu \mathrm{M}$ for $24 \mathrm{~h}$ with selegiline, $\mathrm{n}=58 \mathrm{cells}$; $100 \mu \mathrm{M}$ for 30 min, $\mathrm{n}=42$ cells; and GABA, $\mathrm{n}=45$ cells) and were analyzed using Tukey's multiple comparison test. ${ }^{*} \mathrm{p}<0.05,{ }^{* *} \mathrm{p}<0.01,{ }^{* * *} \mathrm{p}<0.001,{ }^{* * * *} \mathrm{p}<0.0001$.

tion in reactive astrocytes under pathological conditions [40]. We investigated whether MAO-B mediates DA-induced GABA production. To this end, we treated primary cortical astrocytes with DA and selegiline, which is a selective MAO-B inhibitor (Fig. 4A). Long-term treatment with DA for $24 \mathrm{~h}$ increased GABA production in cortical astrocytes, and this effect was significantly $(\mathrm{p}<0.01)$ attenuated by selegiline. However, short-term treatment with DA for $30 \mathrm{~min}$ did not significantly increase GABA production in cortical astrocytes (Fig. 4B, C). Taken together, long-term treatment with DA leads to generation of reactive astrocytes that produce GABA in a MAO-B-dependent manner, while short-term treatment with DA does not.

\section{$D A$ increases GABA production in primary hypothalamic astrocytes}

The hypothalamus is the primary center of metabolic control [41] and contains hypertrophic and hyperplasic astrocytes after long-term feeding of a HFD $[29,42,43]$. Moreover, the BBB is highly fenestrated in the hypothalamus, which enables astrocytes to sense and rapidly respond to circulating nutrients such as free FAs derived from dietary lipids and hormones [4]. Therefore, we investigated whether long-term treatment with DA increases the GABA level in hypothalamic astrocytes, as observed in cortical astrocytes. Similar to cortical astrocytes, hypothalamic astrocytes were split after 11 DIV and incubated with DA after 12 DIV for $24 \mathrm{~h}$ (Fig. 5A). DA treatment increased the GABA level in a dosedependent manner (Fig. 5B). The GABA level was significantly $(\mathrm{p}<0.0001)$ increased by treatment with $100 \mu \mathrm{M}$ DA for $24 \mathrm{~h}$ (Fig. 5C). Together, these findings indicate that long-term treatment with DA increases the GABA level in hypothalamic astrocytes in a dose-dependent manner.

\section{$D A$ increases $G A B A$ production via $M A O-B$ in primary hy- pothalamic astrocytes}

We investigated whether MAO-B mediates DA-induced GABA production in hypothalamic astrocytes, as observed in cortical astrocytes (Fig. 6A). Selegiline significantly $(\mathrm{p}<0.0001)$ attenuated the increase in GABA production induced by treatment with DA 


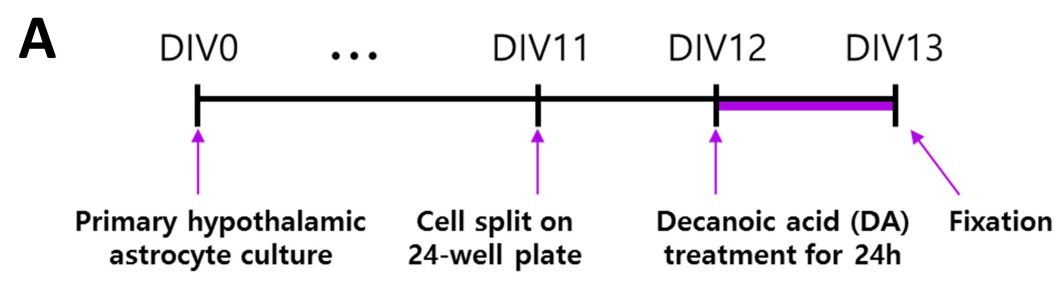

B

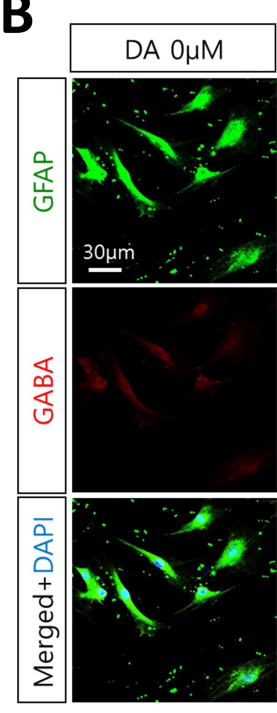

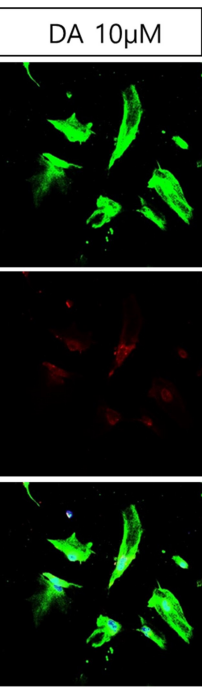
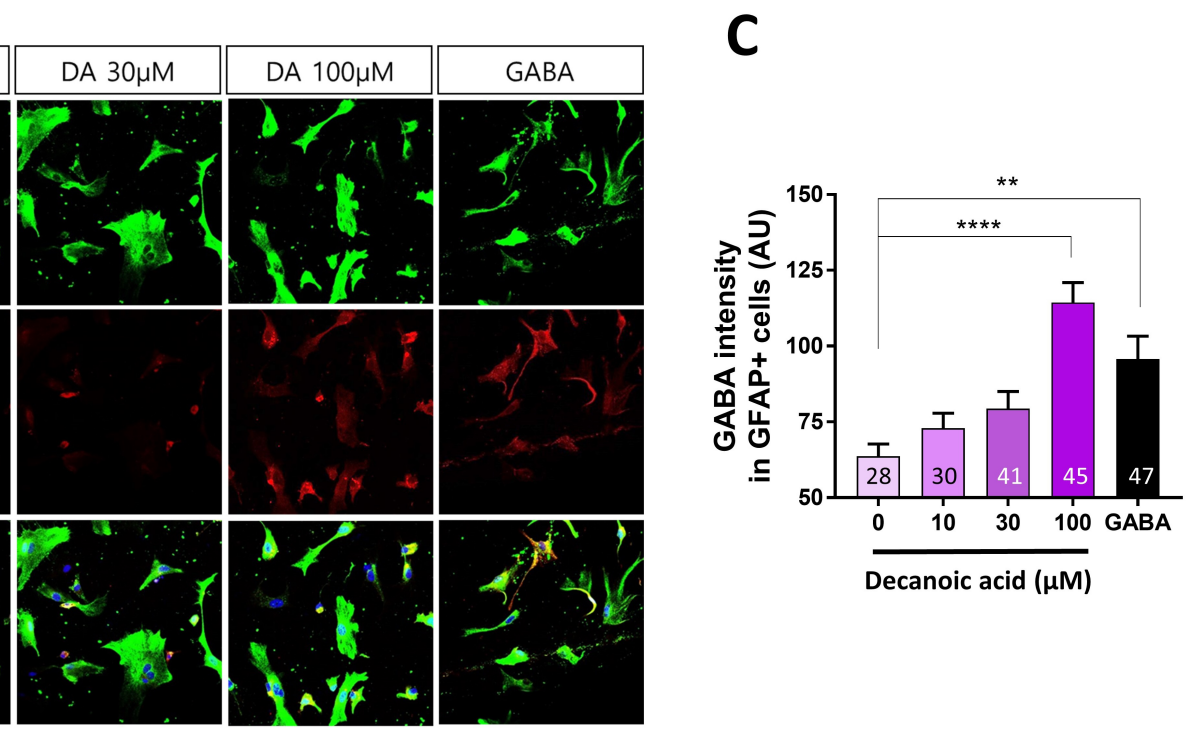

Fig. 5. DA increases GABA production in primary hypothalamic astrocytes. (A) Timeline of treatment of primary hypothalamic astrocytes with different concentrations of DA for $24 \mathrm{~h}$ followed by immunocytochemistry. (B) Representative fluorescence immunocytochemical images of cells treated with different concentrations $(0,10,30$, and $100 \mu \mathrm{M})$ of DA. Cells were treated with $100 \mu \mathrm{M}$ GABA as a positive control. (C) Fluorescence intensity of GABA labeling in GFAP-positive primary hypothalamic astrocytes. All data are shown as mean \pm SEM $(0 \mu \mathrm{M}, \mathrm{n}=28$ cells; $10 \mu \mathrm{M}, \mathrm{n}=30$ cells; $30 \mu \mathrm{M}, \mathrm{n}=41$ cells; $100 \mu \mathrm{M}, \mathrm{n}=45$ cells; and GABA, $\mathrm{n}=47$ cells) and were analyzed using Tukey's multiple comparison test. ${ }^{*} \mathrm{p}<0.05,{ }^{* *} \mathrm{p}<0.01,{ }^{* * *} \mathrm{p}<0.001,{ }^{* * *} \mathrm{p}<0.0001$.

for $24 \mathrm{~h}$ in hypothalamic astrocytes (Fig. 6B, C). In contrast with cortical astrocytes, treatment with DA for 30 min significantly $(\mathrm{p}<0.05)$ increased the GABA level in hypothalamic astrocytes (Fig. 6B, C). These results suggest that the effects of DA on MAOB-dependent GABA production are more acute in hypothalamic astrocytes than in cortical astrocytes.

\section{DISCUSSION}

This study demonstrates for the first time that short-term treatment with DA (C10), a saturated MCFA, increases cAMP formation and lactate release in primary astrocytes via a signaling pathway coupled to a $\mathrm{G}_{\mathrm{as}}-\mathrm{GPCR}$ and tmAC (Fig. 7). Astrocytes may play a critical role by supplying lactate as an energy source to neighboring neurons. By contrast, long-term treatment with DA induces synthesis of GABA via MAO-B by changing the functional characteristics of astrocytes (Fig. 7). Accumulation of $\mathrm{MAO}-\mathrm{B}$-dependent GABA in reactive astrocytes is expected to inhibit neurons. Our study reveals a novel molecular mechanism by which astrocytes recognize free MCFAs and reports the effects of short- and long-term treatment with DA. This unique MCFAGPCR interaction in astrocytes may provide novel insights into the functional basis for control of the energy balance and feeding in the brain.

MCFAs are an important source of ketogenesis to form ketone bodies, which travel to the brain and are used as an alternative energy source by neurons when the blood glucose level is severely reduced during fasting [44]. Whereas hepatic ketogenesis has been well-elucidated, ketogenesis via oxidation of free FAs also occurs in astrocytes in the brain [45]. Although MCFAs are substrates for ketogenesis in astrocytes [45], their cellular signaling functions are mostly unknown. This study reveals that DA has a novel functional role as a signaling molecule by interacting with a GPCR (Figs. 1,2). While long-term treatment with DA induced synthesis of GABA via $\mathrm{MAO}-\mathrm{B}$, short-term treatment with $\mathrm{DA}$ induced lactate release via a $\mathrm{G}_{\mathrm{as}}$-GPCR-tmAC-cAMP pathway. This MCFAGPCR interaction provides novel insights into the functional basis for how astrocytes sense free FAs in the brain. FAs are ligands for 


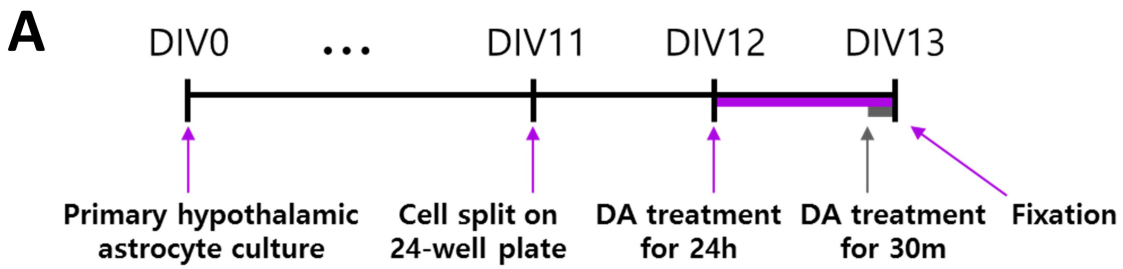

B

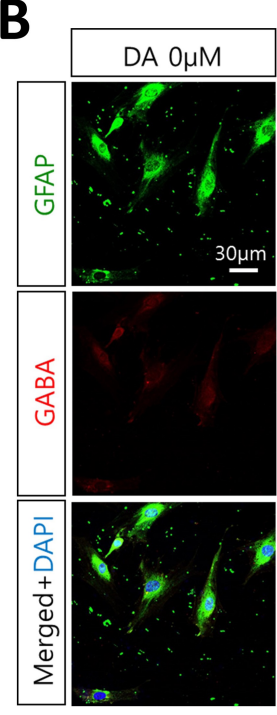

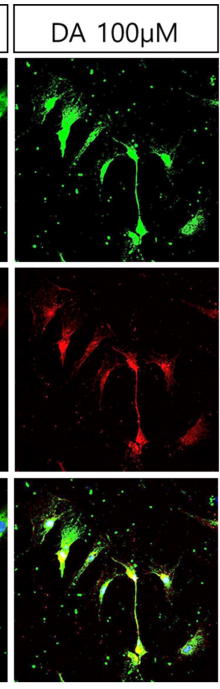

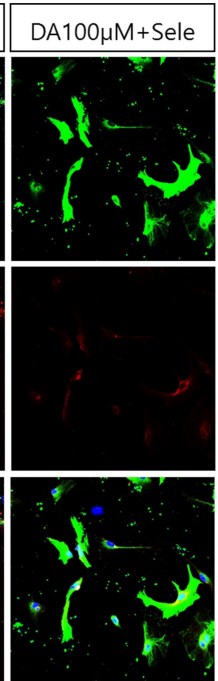

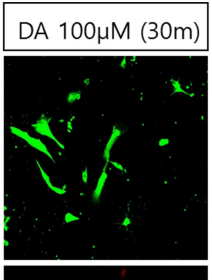
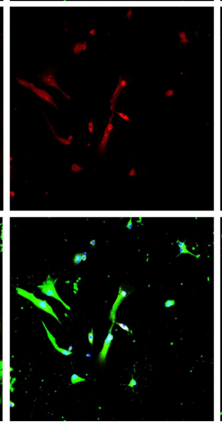

C

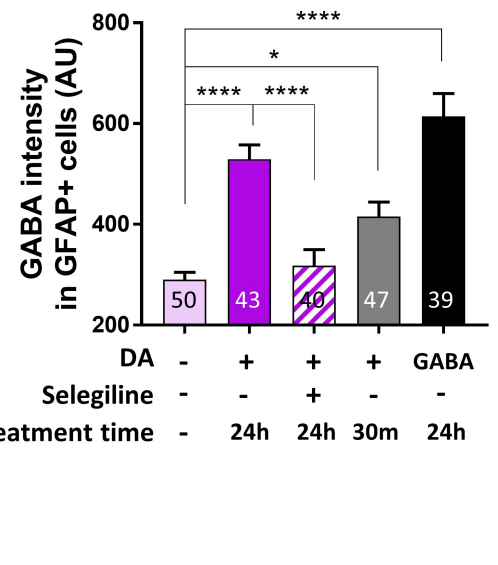

Fig. 6. DA increases GABA production via MAO-B in primary hypothalamic astrocytes. (A) Timeline of treatment of primary hypothalamic astrocytes with DA for $24 \mathrm{~h}$ or $30 \mathrm{~min}$ followed by immunocytochemistry. (B) Representative fluorescence immunocytochemical images of cells treated with 100 $\mu \mathrm{M}$ DA with different durations. Cells were treated with $100 \mu \mathrm{M}$ GABA as a positive control. (C) Fluorescence intensity of GABA labeling in GFAPpositive primary hypothalamic astrocytes. All data are shown as mean \pm SEM $(0 \mu \mathrm{M}, \mathrm{n}=50$ cells; $100 \mu \mathrm{M}$ for $24 \mathrm{~h}, \mathrm{n}=43$ cells; $100 \mu \mathrm{M}$ for $24 \mathrm{~h}$ with selegiline, $\mathrm{n}=40$ cells; $100 \mu \mathrm{M}$ for $30 \mathrm{~min}, \mathrm{n}=47$ cells; and GABA, $\mathrm{n}=39$ cells) and were analyzed using Tukey's multiple comparison test. ${ }^{*} \mathrm{p}<0.05,{ }^{* *} \mathrm{p}<0.01$, ${ }^{* * *} \mathrm{p}<0.001,{ }^{* * * *} \mathrm{p}<0.0001$.
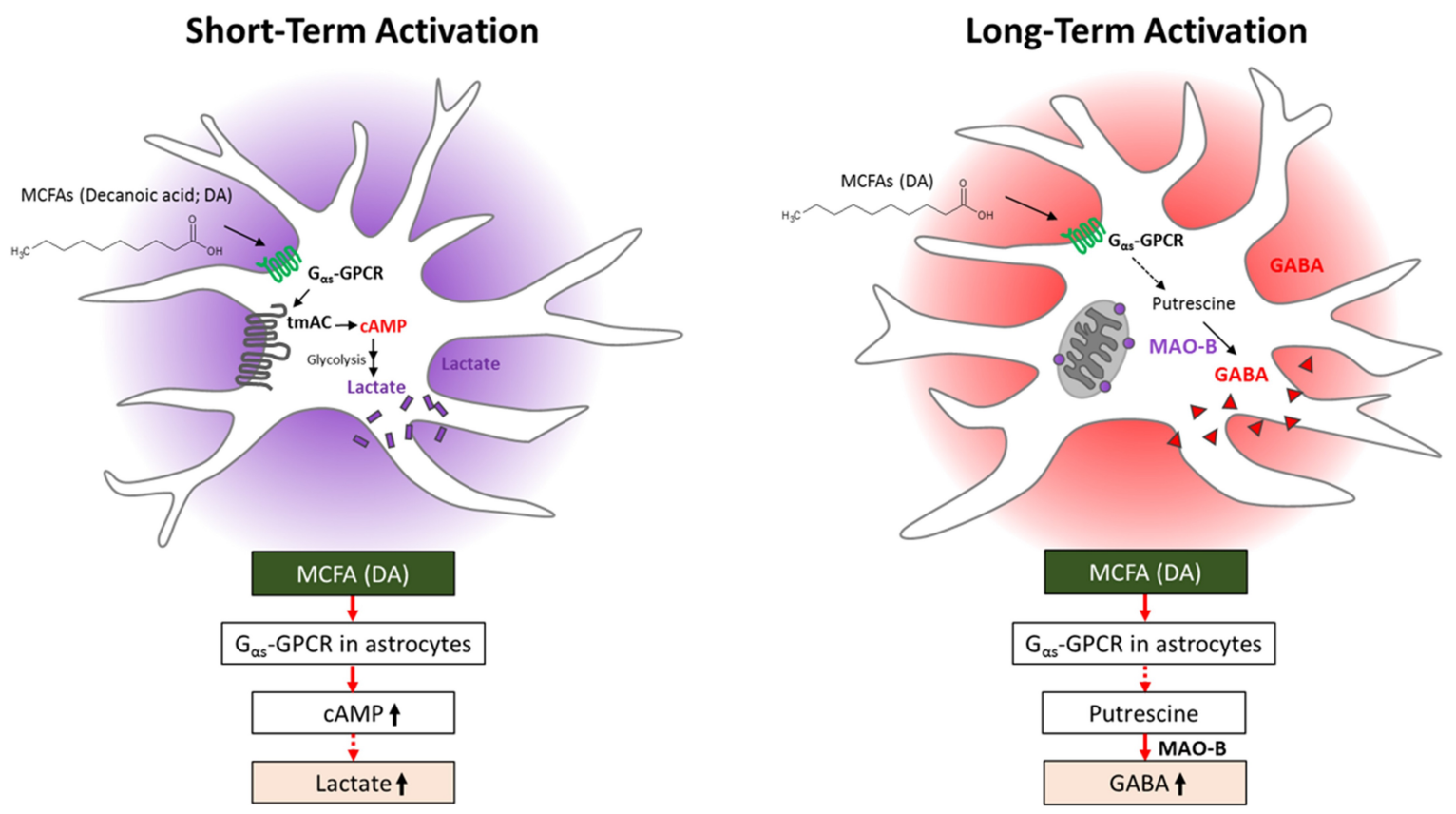

Fig. 7. Effects of short- and long-term treatment with DA on astrocytes. 
many GPCRs. For example, members of the FFAR family recognize free FAs. This family consists of FFAR1/GPR40 and FFAR4/ GPR120, which are activated by medium- and long-chain free FAs, respectively, and FFAR3/GPR41 and FFAR2/GPR43, which are activated by short-chain free FAs [14]. In addition, a recent study revealed that ORs recognize SCFAs and MCFAs in many non-olfactory tissues [17]. Representative examples are Olfr78 [15], Olfr544 [46], and Olfr15 [47, 48], which recognize SCFAs, dicarboxylic MCFAs, and MCFAs, respectively. A further study is required to identify the GPCR that recognizes free MCFAs in astrocytes.

The physiological concentration of MCFAs in the brain and blood required to stimulate astrocytes is an important parameter. MCFAs move rapidly and readily from blood to the brain via the $\mathrm{BBB}$, especially in the hypothalamic region where the BBB is highly fenestrated [11]. MCFAs, particularly OA and DA, elicit beneficial effects on children who suffer from seizures, and consequently such children have been traditionally treated with a medium-chain triglyceride (MCT) diet [49]. OA and DA are detected in plasma at various time points over $24 \mathrm{~h}$ when children are fed a MCT diet. In addition, OA and DA are detected at concentrations of 0.104 2.1 $\mathrm{mM}$ and 12 250 $\mu \mathrm{M}$, respectively, in plasma of mice fed a MCT diet for 4 days [12]. Consistently, the $\mathrm{EC}_{50}$ of DA was 82.5 and 209.2 $\mu \mathrm{M}$ for cAMP production and lactate release, respectively (Figs. 1,2). Taken together, these data suggest that treatment with $\sim 100 \sim 200 \mu \mathrm{M}$ DA is sufficient to stimulate astrocytes in vivo.

The accumulation of cytosolic GABA suggests that long-term treatment with DA triggers an increase in putrescine, which is the major precursor of GABA. How does DA trigger an increase in putrescine? A clue might lie in the findings that DA activated a $\mathrm{G}_{\mathrm{as}}$-GPCR and increased cAMP synthesis in astrocytes. cAMP has been suggested to induce autophagy via beclin 1 , which is a mammalian ortholog of yeast autophagy-related gene 6 [50]. Furthermore, treatment with the cell-permeable cAMP analog 8-CPTcAMP increases the levels of LC3-II and beclin 1 in adipocytederived mesenchymal stem cells [50]. Therefore, an increase in cAMP upon DA treatment may activate autophagy, which allows the orderly degradation and recycling of cellular components in astrocytes [51]. The endocytosed DA- $\mathrm{G}_{\mathrm{as}}-\mathrm{GPCR}$ complex might be degraded to increase the levels of $\mathrm{L}$-arginine and $\mathrm{L}$-ornithine, which are a source of putrescine [52]. Putrescine may then be further degraded via $\mathrm{MAO}-\mathrm{B}$ to produce GABA, a molecular marker of reactive astrocytes [30,32]. These possibilities require further investigations.

What is the relevance of MAO-B-dependent GABA production? MAO-B mediates astrocytic GABA production [32]. We previously demonstrated that astrocytic GABA is released tonically by reactive astrocytes in the hippocampus and is responsible for memory impairment in a mouse model of Alzheimer's disease [33]. Excessive production of GABA upon long-term exposure to DA may inhibit neighboring neurons, especially in the hypothalamus, where the neural circuits responsible for food intake and energy expenditure exist. The roles of astrocytic GABA produced upon long-term exposure to MCFAs in hypothalamic functions, especially food intake and energy expenditure, should be investigated in the future. MAO-B also mediates $\mathrm{H}_{2} \mathrm{O}_{2}$ production $[32,53]$. Reactive astrocytes produce large amounts of reactive oxygen species (ROS), which are chemically reactive chemical species containing oxygen such as $\mathrm{H}_{2} \mathrm{O}_{2}$ [54], in a MAO-B-dependent manner [55, 56]. ROS produced by oxidation of monoamines, such as acetylputrescine [30], induce hypertrophy of astrocytic processes and increase cell proliferation $[55,57,58]$. Long-term exposure to DA may induce excessive ROS production in astrocytes. These exciting possibilities require future investigation.

Our findings suggest that astrocytes play crucial roles in lipidsensing in the brain and modulate metabolism in nearby neurons by releasing lactate and/or GABA. We propose that modulation of lactate and GABA production mediated by a GPCR and MAO-B is a new approach to control energy metabolism in astrocytes.

\section{ACKNOWLEDGEMENTS}

This research was supported by the Brain Research Program through the NRF funded by the Ministry of Science and ICT (2018M3C7A1056682) and by the DGIST R\&D Program of the Ministry of Science, ICT, and Future Planning (18-BD-06, 18-BT02).

\section{REFERENCES}

1. Wang SW, Wang M, Grossman BM, Martin RJ (1994) Effects of dietary fat on food intake and brain uptake and oxidation of fatty acids. Physiol Behav 56:517-522.

2. Karmi A, Iozzo P, Viljanen A, Hirvonen J, Fielding BA, Virtanen K, Oikonen V, Kemppainen J, Viljanen T, Guiducci L, Haaparanta-Solin M, Någren K, Solin O, Nuutila P (2010) Increased brain fatty acid uptake in metabolic syndrome. Diabetes 59:2171-2177.

3. Giles C, Takechi R, Mellett NA, Meikle PJ, Dhaliwal S, Mamo JC (2016) The effects of long-term saturated fat enriched diets on the brain lipidome. PLoS One 11:e0166964.

4. Borg ML, Omran SF, Weir J, Meikle PJ, Watt MJ (2012) Consumption of a high-fat diet, but not regular endurance exercise training, regulates hypothalamic lipid accumulation in 
mice. J Physiol 590:4377-4389.

5. Posey KA, Clegg DJ, Printz RL, Byun J, Morton GJ, Vivekanandan-Giri A, Pennathur S, Baskin DG, Heinecke JW, Woods SC, Schwartz MW, Niswender KD (2009) Hypothalamic proinflammatory lipid accumulation, inflammation, and insulin resistance in rats fed a high-fat diet. Am J Physiol Endocrinol Metab 296:E1003-E1012.

6. Bourre JM, Pascal G, Durand G, Masson M, Dumont O, Piciotti M (1984) Alterations in the fatty acid composition of rat brain cells (neurons, astrocytes, and oligodendrocytes) and of subcellular fractions (myelin and synaptosomes) induced by a diet devoid of n-3 fatty acids. J Neurochem 43:342-348.

7. Bernoud N, Fenart L, Bénistant C, Pageaux JF, Dehouck MP, Molière P, Lagarde M, Cecchelli R, Lecerf J (1998) Astrocytes are mainly responsible for the polyunsaturated fatty acid enrichment in blood-brain barrier endothelial cells in vitro. J Lipid Res 39:1816-1824.

8. Gupta S, Knight AG, Gupta S, Keller JN, Bruce-Keller AJ (2012) Saturated long-chain fatty acids activate inflammatory signaling in astrocytes. J Neurochem 120:1060-1071.

9. Tsuji A (2005) Small molecular drug transfer across the blood-brain barrier via carrier-mediated transport systems. NeuroRx 2:54-62.

10. Vijay N, Morris ME (2014) Role of monocarboxylate transporters in drug delivery to the brain. Curr Pharm Des 20:1487-1498.

11. Ebert D, Haller RG, Walton ME (2003) Energy contribution of octanoate to intact rat brain metabolism measured by 13C nuclear magnetic resonance spectroscopy. J Neurosci 23:5928-5935.

12. Dean HG, Bonser JC, Gent JP (1989) HPLC analysis of brain and plasma for octanoic and decanoic acids. Clin Chem 35:1945-1948.

13. Schönfeld P, Wojtczak L (2016) Short- and medium-chain fatty acids in energy metabolism: the cellular perspective. J Lipid Res 57:943-954.

14. Hara T, Kashihara D, Ichimura A, Kimura I, Tsujimoto G, Hirasawa A (2014) Role of free fatty acid receptors in the regulation of energy metabolism. Biochim Biophys Acta 1841:12921300 .

15. Pluznick JL, Protzko RJ, Gevorgyan H, Peterlin Z, Sipos A, Han J, Brunet I, Wan LX, Rey F, Wang T, Firestein SJ, Yanagisawa M, Gordon JI, Eichmann A, Peti-Peterdi J, Caplan MJ (2013) Olfactory receptor responding to gut microbiotaderived signals plays a role in renin secretion and blood pressure regulation. Proc Natl Acad Sci U S A 110:4410-4415.

16. Pluznick J (2014) A novel SCFA receptor, the microbiota, and blood pressure regulation. Gut Microbes 5:202-207.

17. Kang N, Koo J (2012) Olfactory receptors in non-chemosensory tissues. BMB Rep 45:612-622.

18. Thevenet J, De Marchi U, Domingo JS, Christinat N, Bultot L, Lefebvre G, Sakamoto K, Descombes P, Masoodi M, Wiederkehr A (2016) Medium-chain fatty acids inhibit mitochondrial metabolism in astrocytes promoting astrocyteneuron lactate and ketone body shuttle systems. FASEB J 30:1913-1926.

19. Pellerin L, Magistretti PJ (1994) Glutamate uptake into astrocytes stimulates aerobic glycolysis: a mechanism coupling neuronal activity to glucose utilization. Proc Natl Acad Sci U S A 91:10625-10629.

20. Itoh Y, Esaki T, Shimoji K, Cook M, Law MJ, Kaufman E, Sokoloff L (2003) Dichloroacetate effects on glucose and lactate oxidation by neurons and astroglia in vitro and on glucose utilization by brain in vivo. Proc Natl Acad Sci U S A 100:4879-4884.

21. Herrero-Mendez A, Almeida A, Fernández E, Maestre C, Moncada S, Bolaños JP (2009) The bioenergetic and antioxidant status of neurons is controlled by continuous degradation of a key glycolytic enzyme by APC/C-Cdh1. Nat Cell Biol 11:747-752.

22. Pakkenberg B, Gundersen HJ (1988) Total number of neurons and glial cells in human brain nuclei estimated by the disector and the fractionator. J Microsc 150:1-20.

23. Sherwood CC, Stimpson CD, Raghanti MA, Wildman DE, Uddin M, Grossman LI, Goodman M, Redmond JC, Bonar CJ, Erwin JM, Hof PR (2006) Evolution of increased glianeuron ratios in the human frontal cortex. Proc Natl Acad Sci U S A 103:13606-13611.

24. Blázquez C, Sánchez C, Velasco G, Guzmán M (1998) Role of carnitine palmitoyltransferase I in the control of ketogenesis in primary cultures of rat astrocytes. J Neurochem 71:15971606.

25. Buckman LB, Thompson MM, Lippert RN, Blackwell TS, Yull FE, Ellacott KL (2014) Evidence for a novel functional role of astrocytes in the acute homeostatic response to high-fat diet intake in mice. Mol Metab 4:58-63.

26. Argente-Arizón P, Freire-Regatillo A, Argente J, Chowen JA (2015) Role of non-neuronal cells in body weight and appetite control. Front Endocrinol (Lausanne) 6:42.

27. García-Cáceres C, Fuente-Martín E, Argente J, Chowen JA (2012) Emerging role of glial cells in the control of body weight. Mol Metab 1:37-46.

28. No authors listed (1968) Nutritional value of medium chain triglycerides. Nutr Rev 26:352. 
29. Thaler JP, Yi CX, Schur EA, Guyenet SJ, Hwang BH, Dietrich MO, Zhao X, Sarruf DA, Izgur V, Maravilla KR, Nguyen HT, Fischer JD, Matsen ME, Wisse BE, Morton GJ, Horvath TL, Baskin DG, Tschöp MH, Schwartz MW (2012) Obesity is associated with hypothalamic injury in rodents and humans. J Clin Invest 122:153-162.

30. Chun H, An H, Lim J, Woo J, Lee J, Ryu H, Lee CJ (2018) Astrocytic proBDNF and tonic GABA distinguish active versus reactive astrocytes in hippocampus. Exp Neurobiol 27:155170.

31. Marmigère F, Rage F, Tapia-Arancibia L (2003) GABAglutamate interaction in the control of BDNF expression in hypothalamic neurons. Neurochem Int 42:353-358.

32. Yoon BE, Woo J, Chun YE, Chun H, Jo S, Bae JY, An H, Min JO, Oh SJ, Han KS, Kim HY, Kim T, Kim YS, Bae YC, Lee CJ (2014) Glial GABA, synthesized by monoamine oxidase B, mediates tonic inhibition. J Physiol 592:4951-4968.

33. Jo S, Yarishkin O, Hwang YJ, Chun YE, Park M, Woo DH, Bae JY, Kim T, Lee J, Chun H, Park HJ, Lee DY, Hong J, Kim HY, Oh SJ, Park SJ, Lee H, Yoon BE, Kim Y, Jeong Y, Shim I, Bae YC, Cho J, Kowall NW, Ryu H, Hwang E, Kim D, Lee CJ (2014) GABA from reactive astrocytes impairs memory in mouse models of Alzheimer's disease. Nat Med 20:886-896.

34. Tamashiro TT, Dalgard CL, Byrnes KR (2012) Primary microglia isolation from mixed glial cell cultures of neonatal rat brain tissue. J Vis Exp e3814.

35. Choi HB, Gordon GR, Zhou N, Tai C, Rungta RL, Martinez J, Milner TA, Ryu JK, McLarnon JG, Tresguerres M, Levin LR, Buck J, MacVicar BA (2012) Metabolic communication between astrocytes and neurons via bicarbonate-responsive soluble adenylyl cyclase. Neuron 75:1094-1104.

36. Buck J, Sinclair ML, Schapal L, Cann MJ, Levin LR (1999) Cytosolic adenylyl cyclase defines a unique signaling molecule in mammals. Proc Natl Acad Sci U S A 96:79-84.

37. Bitterman JL, Ramos-Espiritu L, Diaz A, Levin LR, Buck J (2013) Pharmacological distinction between soluble and transmembrane adenylyl cyclases. J Pharmacol Exp Ther 347:589-598.

38. Zhang Y, Chen K, Sloan SA, Bennett ML, Scholze AR, O'Keeffe S, Phatnani HP, Guarnieri P, Caneda C, Ruderisch N, Deng S, Liddelow SA, Zhang C, Daneman R, Maniatis T, Barres BA, Wu JQ (2014) An RNA-sequencing transcriptome and splicing database of glia, neurons, and vascular cells of the cerebral cortex. J Neurosci 34:11929-11947.

39. Zhang Y, Sloan SA, Clarke LE, Caneda C, Plaza CA, Blumenthal PD, Vogel H, Steinberg GK, Edwards MS, Li G, Duncan JA 3rd, Cheshier SH, Shuer LM, Chang EF, Grant GA, Geph- art MG, Barres BA (2016) Purification and characterization of progenitor and mature human astrocytes reveals transcriptional and functional differences with mouse. Neuron 89:3753.

40. Yoon BE, Woo J, Lee CJ (2012) Astrocytes as GABA-ergic and GABA-ceptive cells. Neurochem Res 37:2474-2479.

41. Balland E, Dam J, Langlet F, Caron E, Steculorum S, Messina A, Rasika S, Falluel-Morel A, Anouar Y, Dehouck B, Trinquet E, Jockers R, Bouret SG, Prévot V (2014) Hypothalamic tanycytes are an ERK-gated conduit for leptin into the brain. Cell Metab 19:293-301.

42. Valdearcos M, Robblee MM, Benjamin DI, Nomura DK, Xu AW, Koliwad SK (2014) Microglia dictate the impact of saturated fat consumption on hypothalamic inflammation and neuronal function. Cell Reports 9:2124-2138.

43. Buckman LB, Thompson MM, Moreno HN, Ellacott KL (2013) Regional astrogliosis in the mouse hypothalamus in response to obesity. J Comp Neurol 521:1322-1333.

44. Hawkins RA, Biebuyck JF (1979) Ketone bodies are selectively used by individual brain regions. Science 205:325-327.

45. Auestad N, Korsak RA, Morrow JW, Edmond J (1991) Fatty acid oxidation and ketogenesis by astrocytes in primary culture. J Neurochem 56:1376-1386.

46. Kang N, Bahk YY, Lee N, Jae Y, Cho YH, Ku CR, Byun Y, Lee EJ, Kim MS, Koo J (2015) Olfactory receptor Olfr544 responding to azelaic acid regulates glucagon secretion in a-cells of mouse pancreatic islets. Biochem Biophys Res Commun 460:616-621.

47. Munakata Y, Yamada T, Imai J, Takahashi K, Tsukita S, Shirai Y, Kodama S, Asai Y, Sugisawa T, Chiba Y, Kaneko K, Uno K, Sawada S, Hatakeyama H, Kanzaki M, Miyazaki JI, Oka Y, Katagiri H (2018) Olfactory receptors are expressed in pancreatic $\beta$-cells and promote glucose-stimulated insulin secretion. Sci Rep 8:1499.

48. Leem J, Shim HM, Cho H, Park JH (2018) Octanoic acid potentiates glucose-stimulated insulin secretion and expression of glucokinase through the olfactory receptor in pancreatic $\beta$-cells. Biochem Biophys Res Commun 503:278-284.

49. Bach AC, Babayan VK (1982) Medium-chain triglycerides: an update. Am J Clin Nutr 36:950-962.

50. Ugland H, Naderi S, Brech A, Collas P, Blomhoff HK (2011) cAMP induces autophagy via a novel pathway involving ERK, cyclin E and Beclin 1. Autophagy 7:1199-1211.

51. Mizushima N, Komatsu M (2011) Autophagy: renovation of cells and tissues. Cell 147:728-741.

52. Reitzer L, Schneider BL (2001) Metabolic context and possible physiological themes of sigma(54)-dependent genes in 
Escherichia coli. Microbiol Mol Biol Rev 65:422-444.

53. Mallajosyula JK, Kaur D, Chinta SJ, Rajagopalan S, Rane A, Nicholls DG, Di Monte DA, Macarthur H, Andersen JK (2008) MAO-B elevation in mouse brain astrocytes results in Parkinson's pathology. PLoS One 3:e1616.

54. Hayyan M, Hashim MA, AlNashef IM (2016) Superoxide ion: generation and chemical implications. Chem Rev 116:30293085.

55. Borroni E, Bohrmann B, Grueninger F, Prinssen E, Nave S, Loetscher H, Chinta SJ, Rajagopalan S, Rane A, Siddiqui A, Ellenbroek B, Messer J, Pähler A, Andersen JK, Wyler R, Cesura AM (2017) Sembragiline: a novel, selective monoamine oxidase type $b$ inhibitor for the treatment of Alzheimer's disease.
J Pharmacol Exp Ther 362:413-423.

56. Pizzinat N, Copin N, Vindis C, Parini A, Cambon C (1999) Reactive oxygen species production by monoamine oxidases in intact cells. Naunyn Schmiedebergs Arch Pharmacol 359:428-431.

57. de Pablo Y, Nilsson M, Pekna M, Pekny M (2013) Intermediate filaments are important for astrocyte response to oxidative stress induced by oxygen-glucose deprivation and reperfusion. Histochem Cell Biol 140:81-91.

58. Sauer H, Wartenberg M, Hescheler J (2001) Reactive oxygen species as intracellular messengers during cell growth and differentiation. Cell Physiol Biochem 11:173-186. 